\title{
Epidemiology and Clinical Characteristics of Non-Hodgkin Lymphoma in Mexico
}

\author{
Eleazar Hernandez-Ruiz ${ }^{\mathrm{a}, \mathrm{b}, \mathrm{e}}$, Martha Alvarado-Ibarrab, p, Lourdes Esthela Juan Lien-Chang ${ }^{\mathrm{c}}$, \\ Luisa Banda-Garcia ${ }^{d}$, Jorge Luis Aquino-Salgado ${ }^{a}$, Gabriel Barragan-Ibanez ${ }^{\text {a }}$, \\ Eva Fabiola Ramirez-Romero ${ }^{\mathrm{e}}$, Cesar Nolasco-Cancino, $\mathrm{g}$, Wilfrido Herrera-Olivares ${ }^{\mathrm{h}}$, \\ Javier de Jesus Morales-Adrian ${ }^{\mathrm{i}}$, Eugenia Patricia Paredes-Lozanoj, Maria Eugenia Espitia-Rios ${ }^{\mathrm{b}}$, \\ Maria de Monserrat Gonzalez Lopez-Elizalde ${ }^{\mathrm{k}}$, Jose Luis Lopez-Arroyo, Jorge Enrique Trejo-Gomoram ${ }^{\mathrm{m}}$, \\ Jose Antonio De la Pena-Celaya ${ }^{\mathrm{b}}$, Jose Luis Alvarez-Vera ${ }^{\mathrm{b}}$, Luara Luz Arana-Luna ${ }^{\mathrm{b}}$, Annel Martinez-Rios ${ }^{\mathrm{n}}$, \\ Rodrigo Resendiz-Olea ${ }^{\mathrm{n}}$, Lucero Jazmin Rodriguez-Velasquez ${ }^{\mathrm{a}}$, Nidia Zapata-Canto ${ }^{\circ}$, \\ Juan Manuel Perez-Zuniga ${ }^{\text {b, n, }} \mathrm{p}$
}

\begin{abstract}
Background: There is no epidemiological registry in Mexico. The information about the epidemiology in our country is obtained by
\end{abstract}

Manuscript submitted December 4, 2020, accepted January 4, 2021

Published online February 24, 2021

${ }^{\text {aS }}$ Servicio de Hematologia, Hospital Regional de Alta Especialidad, de Oaxaca, Oaxaca, Mexico

bServicio de Hematologia, Centro Medico Nacional "20 de Noviembre", ISSSTE, Mexico City, Mexico

${ }^{\mathrm{c} S}$ Servicio de Hematologia, Unidad de Oncologia y Servicios de Salud del Estado de Puebla, Puebla, Mexico

${ }^{\mathrm{d} S e r v i c i o}$ de Hematologia, Hospital General de Zona No. 11 de Xalapa, Veracruz, Mexico

eServicio de Hematologia, Hospital Regional Presidente Juarez de Oaxaca, ISSSTE, Oaxaca, Mexico

fServicio de Hematologia, Hospital Regional Doctor Juan Graham Casasus de Villahermosa, Tabasco, Mexico

${ }^{g}$ Servicio de Hematologia, Hospital CERACOM, Villahermosa, Tabasco, Mexico

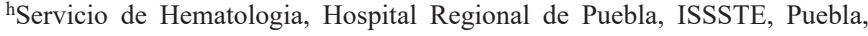
Mexico

iServicio de Hematologia, Hospital Regional de Merida, ISSSTE, Yucatan, Mexico

${ }^{j}$ Servicio de Hematologia, Hospital Regional $1^{\circ}$ de Octubre ISSSTE, Mexico City, Mexico

${ }^{k}$ Servicio de Hematologia, Hospital H+ de Queretaro, Queretaro, Mexico

${ }^{1}$ Servicio de Hematologia, Hospital General B de Ciudad Juarez, Chihuahua, Mexico

mServicio de Hematologia, Hospital San Angel Inn Universidad, Mexico City, Mexico

${ }^{\mathrm{n} S}$ Servicio de Hematologia, Hospital Regional Ignacio Zaragoza ISSSTE, Mexico City, Mexico

'Instituto Nacional de Cancerologia, Mexico City, Mexico

${ }^{\mathrm{p} C o r r e s p o n d i n g ~ A u t h o r s: ~ J u a n ~ M a n u e l ~ P e r e z ~ Z u n i g a ~ a n d ~ M a r t h a ~ A l v a r a d o ~}$ Ibarra, Servicio de Hematologia, Centro Medico Nacional "20 de Noviembre”, ISSSTE, Mexico City, Mexico Mexico. Emails: kbzaz@hotmail.com and normoblasto@gmail.com

doi: https://doi.org/10.14740/wjon1351 these types of studies, such as multicentric studies. A lot of improvements in the survival in non-Hodgkin lymphoma patients had occurred in the last 20 years. The access to treatment in these types of pathology could change the prognostic factors in Mexican Mestizos patients. The primary objective of the study was to learn what the most frequent histological varieties of non-Hodgkin lymphoma in Mexico are. The secondary objectives included clinical characteristics, treatments used, treatment response, disease-free survival and overall survival.

Methods: A retrospective, descriptive study of consecutive cases was carried out in 14 hospitals across 14 Mexican states with patients diagnosed with non-Hodgkin lymphoma using the World Health Organization (WHO) 2008 criteria. Inclusion criteria included: $\geq 18$ years of age, male or female, any clinical stage at diagnosis, who had received any chemotherapy regimen, with a known outcome. Descriptive statistics was performed for all variables, and survival was assessed using Kaplan-Meier curves.

Results: Totally, 609 patients were enrolled, of which 545 were Bcell lymphomas and 64 were T-cell lymphomas. Median ages were 61 and 50, respectively. B-cell lymphomas were more common in males with $52.1 \%$, and $65.5 \%$ of T-cell lymphomas occurred in females. For B-cell lymphomas, the two most frequent histological subtypes were diffuse large B-cell lymphoma in $63.9 \%$, followed by follicular lymphoma at $18 \%$. Meanwhile, $50 \%$ of T-cell lymphomas were of the T/natural killer (NK) subtype, and $87.1 \%$ of the patients received a CHOP-like regimen. Radiotherapy was given to $31 \%$ of B-cell Lymphomas and $46.9 \%$ of T-cell lymphomas. Overall survival at 9 years was $84.6 \%$ for B-cell lymphomas, and $73.4 \%$ for T-cell lymphomas.

Conclusions: Diffuse large B-cell lymphoma constitutes the most frequent subtype for B-cell lymphomas in Mexico. The most frequent T-cell lymphoma is the NK/T histological subtype.

Keywords: Non-Hodgkin lymphoma; Histological subtype; B-cell lymphomas; NK/T-cell lymphoma; Chemotherapy regimen 


\section{Introduction}

Non-Hodgkin lymphoma (NHL) is a heterogeneous group of lymphoid tissue neoplasms [1], usually characterized by an increase in proliferation [2] and/or reduction of apoptosis [3], with a subsequent accumulation of lymphoid tissue at a nodal or extra nodal site [4]. Tumor micro-environment plays a pivotal role in disease development, and at least three mechanisms have been described for this group of lymphoid neoplasms. The first mechanism is proliferation, like in the case of Burkitt's lymphoma, which generates a "deletion" of cells from the micro-environment; the second and third mechanisms are "re-education", observed in follicular lymphoma, and "recruitment" of various cells into the tumor, like in the case of Hodgkin lymphoma [5]. These mechanisms condition countless molecular and cellular environments for this disease [6].

NHLs correspond to $90 \%$ of all lymphoid tissue neoplasms, with the remaining $10 \%$ belonging to Hodgkin lymphoma [7]. NHLs frequently are B lineage in almost in $95 \%$ of the cases, and only 5\% are of T lineage [8]. Being a heterogeneous group in lineage, molecular characteristics, ontogeny, clinical stage and affected sites, treatment approaches are usually different, ranging from watch and wait to chemotherapy, immunotherapy, targeted therapy, radiotherapy, and bone marrow transplant [9]. Survival in each type of lymphoma has been clarified due to the great heterogeneity of this disease as well as the identification of prognostic factors related to survival, with the most widespread one being the International Prognostic Index (IPI) [10]. Over time, new histological and molecular classifications, such as those proposed by the World Health Organization (WHO) [11], have helped to discriminate the diagnosis, clinical stage and ideal treatment for each subtype of the disease.

In Mexico, NHL is the ninth cause of cancer, making up $3.1 \%$ of all cancers. In 2012 there was a prevalence of 8,700 cases; there were 4,632 new reported cases and 2,558 deaths attributed to this disease [12]. Based on the information from various public and private institutions that treat these kinds of patients, gaining better insight of the epidemiology of this disease in Mexico must be of the utmost importance, and this is the first effort to obtain nation-wide statistics on this disease.

\section{Patients and Methods}

\section{Design}

A retrospective, observational, descriptive, multi-center study was carried out in 14 hospitals in 14 states of the country, between January 2008 and December 2016. The protocol of this study was approved by the Ethics Committee; the study complies with the Declaration of Helsinki, and was in accordance with the guidelines of good clinical practice and compliance with the regulations of the general health law in the field of health research in Mexico.

\section{Inclusion and exclusion criteria}

Patients with a diagnosis of NHL were included. Diagnosis of histological subtype, with the use of immunohistochemistry, was made by the department of pathology of each institution, and was based on WHO 2008 [13] criteria for classification of lymphoma. Adult patients over the age of 18, off any gender, clinical stage, with any treatment received and known were included. Response was determined by Cheson's 1999 criteria [14] for standardization of lymphoid neoplasms. Patients without complete data were excluded for the study.

\section{Objectives}

The primary objective of the study was to learn what the most frequent histological varieties of NHL in Mexico are. The secondary objectives included clinical characteristics, treatments used, treatment response, disease-free survival and overall survival.

\section{Statistical analysis}

The statistical analysis was performed in SPSS version 23 of IBM, performing descriptive statistics. For treatment response, intention to treat was conducted in all cases. Survival was determined by the Kaplan-Meier method.

\section{Results}

From January 2008 to December 2017, 643 patients were registered; 34 were excluded because they lacked complete data for this study. Median age was 59 years, 50.2\% of patients were females, and $89.5 \%$ of cases were B-cell lymphomas. Clinical stage III - IV as per modified Ann Arbor was documented in $54.4 \%$ of the cases. Performance status, determined by Eastern Cooperative Oncology Group (ECOG) scale, was $0-2$ in $94.7 \%$ of the cases. Complete clinical characteristics are presented in Table 1.

Regarding the histological varieties identified, diffuse large B-cell lymphoma was the most frequent subtype. Natural killer (NK)/T-cell lymphoma was the most frequent histological subtype when it came to T-lineage lymphomas. Table 2 describes the main histological varieties for each group.

When analyzing the most used treatment in this group of patients, the CHOP-21 regimen was applied to $87.1 \%$ of the patients; $91.3 \%$ of patients with B-cell lymphoma received the CHOP-21 chemotherapy regimen, while $53.2 \%$ of patients with T-cell lymphoma also received this same treatment. Rituximab was applied in $74.7 \%$ of B-cell lymphomas. Radiotherapy was applied in $32.7 \%$ of cases. Only $31 \%$ of B-cell lymphomas received radiotherapy, whereas in T-cell lymphomas it was applied to $46.9 \%$ of cases.

The overall response in the group analyzed was $88 \%$, with $74.9 \%$ complete responses. When analyzing overall response by lineage, B-cell lymphomas had an overall response rate of 
Table 1. Clinical Characteristics and Disease Stage Classification

\begin{tabular}{|c|c|c|c|c|}
\hline & Total $(n=609)$ & Type B $(n=545)$ & Type $T(n=64)$ & $\mathbf{P}$ \\
\hline Age (years) & $59(48-70)$ & $61(50-70)$ & $50(39-63)$ & $<0.05$ \\
\hline Gender (female/male) $(\%)$ & $50.2 / 49.8$ & $47.9 / 52.1$ & $65.6 / 34.4$ & $<0.05$ \\
\hline \multicolumn{5}{|l|}{ Ann Arbor $(\%)$} \\
\hline I - II & 45.6 & 44.9 & 51.6 & NS \\
\hline III - IV & 54.4 & 55.1 & 48.4 & \\
\hline$\geq 3$ & 5.3 & 5 & 7.7 & \\
\hline Symptoms B (\%) & 23.3 & 23.5 & 21.9 & NS \\
\hline Bulky (\%) & 27.1 & 28.6 & 14.1 & $<0.05$ \\
\hline \multicolumn{5}{|l|}{ IPI } \\
\hline High & 29.8 & 29.8 & 30 & \\
\hline
\end{tabular}

Age is reported as a median, with 25th and 75th percentiles. Age differences were conducted by median comparison with Mann-Whitney U. For the other variables, a Chi-squared test was conducted. ECOG: Eastern Cooperative Oncology Group; IPI: International Prognostic Index; NS: not significant.

$89.9 \%$, of which $77 \%$ reached a complete response. In T-cell lymphomas, the overall response rate achieved was $71.9 \%$ with only $51.6 \%$ of these being complete responses.

Overall survival, determined at 9 years, was observed in

Table 2. Pathological Classification of Non-Hodgkin Lymphoma by Cell Type and Percentage

\begin{tabular}{|c|c|}
\hline \multicolumn{2}{|l|}{ Type B $(\mathrm{n}=545)$} \\
\hline Diffuse large cell lymphoma & 63.9 \\
\hline Follicular & 18 \\
\hline Small lymphocytes & 4.2 \\
\hline Mantle cell & 3.9 \\
\hline MALT & 3.1 \\
\hline Lymphoblastic & 1.7 \\
\hline Marginal zone & 1.1 \\
\hline Burkitt & 0.9 \\
\hline Others & 3.2 \\
\hline \multicolumn{2}{|l|}{ Type T $(n=64)$} \\
\hline $\mathrm{T} / \mathrm{NK}$ & 50 \\
\hline Mycosis fungoides & 10.9 \\
\hline $\mathrm{T}$ peripheral & 6.3 \\
\hline Anaplastic & 3.1 \\
\hline Lymphoblastic & 3.1 \\
\hline Unspecified $\mathrm{T}$ & 16.6 \\
\hline Others & 10 \\
\hline
\end{tabular}

MALT: mucosa-associated lymphoid tissue; NK: natural killer.
$83.4 \%$ of the cases. When an analysis of survival based on the lineage was done, $84.6 \%$ overall survival was seen in B-cell lymphomas, and $73.4 \%$ in T-cell lymphomas (Fig. 1).

\section{Discussion}

In the present study, diffuse large B-cell lymphoma occurred in $63.9 \%$ of all diagnosed cases of NHL. This is in contrast with what has been published in numerous studies, where approximately $40 \%$ of the cases correspond to this histological subtype [15]. Even in developed countries in different continents, as reported by Perry et al [16], diffuse large B-cell lymphomas account for $42.5 \%$ of all cases. On the other hand, there was a reduction in the prevalence of follicular lymphoma, which was of $18 \%$ in this study, lower than in international reports, where its reported frequency is of up to $30 \%$ [17].

Meanwhile, the most frequent T-cell lymphoma corresponded to the NK/T variety, accounting for $50 \%$ of the cases, higher than the average reported elsewhere. In their review, Aozasa et al [18] reported a frequency of $8-40 \%$.

One of the limitations of this study was that cases were classified in each institution using the 2008 WHO's classification criteria, and there was no centralized review of the cases. This might have impacted the difference in frequencies we reported in this study when compared to international data. In summary 4,727 presented at ASH 2018, Solano et al [19] stated that in up to half the cases of diagnosed NHL; there were inconsistencies between the local pathologists and hematopathologists located in Mexico. This presents an opportunity for future collaboration for the standardization of diagnostic processes for NHL. 


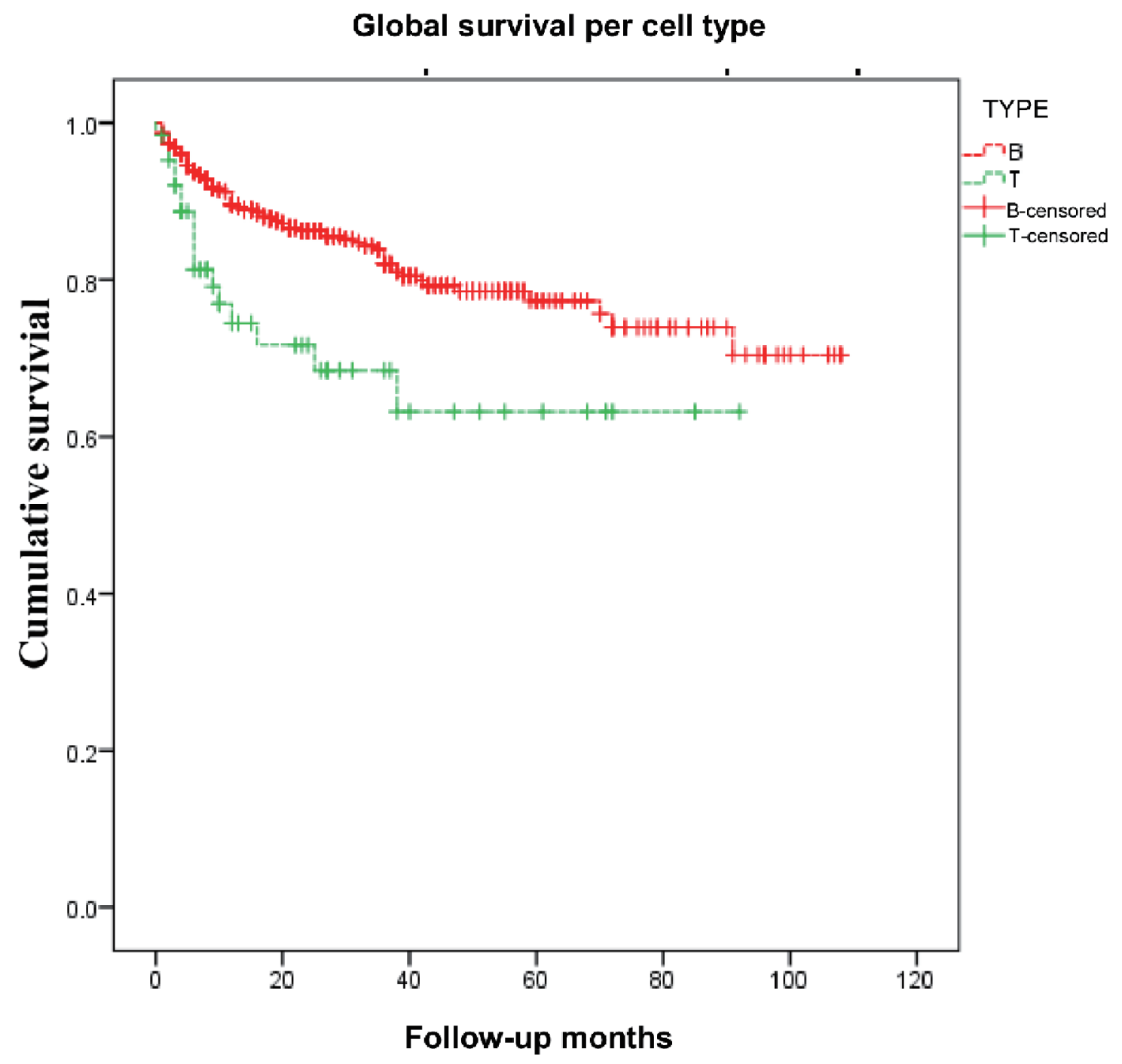

Figure 1. Overall survival curves by cell type, B-cell non-Hodgkin lymphoma and T-cell non-Hodgkin lymphoma.

Treatment with CHOP-like regimens was the most frequently used, which is consistent with the descriptions of $\mathrm{Ku}$ mar et al [20], Hu et al [21] in advanced disease, and Schmitz et al [22], in aggressive T-cell lymphomas.

Only $74.7 \%$ of patients with B-cell lymphomas received rituximab, a smaller number than the average in other reports. Jo et al [23] reported in 2010 that only 4\% of B-cell lymphomas are negative for CD20, so rituximab is used in $96 \%$ of these patients. This study included institutions with no access to rituximab, which might explain the reduced percentage of patients that did receive treatment with this drug.

Radiotherapy was used in one out of every three cases of B-cell lymphomas, consistent with the current international average. However, Zimmermann et al [24] stated in 2016 that there exists a downward tendency when it comes to the use of radiotherapy (47\% since the year 2000$)$, which might play a deleterious role in overall and disease-free survival.

Overall survival in our study at 9 years was $83.4 \%$, higher than reported in consolidated surveillance programs [25].
These results can be attributed to the fact that the patients we included had different histological varieties, as reported by Ji et al [26]; half of the patients were in early stages and one-third were low risk for IPI, additionally, $90 \%$ had ECOG less than 2, important factors for survival as reported by the International Non-Hodgkin's Lymphoma Prognostic Factors Projects [10, 27] in favor of low risks, early stages and better functional status; finally, in our study, patients with poor functional status who did not receive treatment for NHL were excluded.

This study has its limitations: its retrospective design, from different medical centers with diagnosis being made by local pathologists; its registered consecutive cases with local incidences and no restrictions, which might lead to biases in reporting the frequency of NHL. However, it is also the first effort made to have better knowledge of the epidemiology of this disease in Mexico. There is no doubt this must progress and generate more solid and systematic prospective studies. With these new studies, a centralized review of each case should be implemented, improving classification, reproducibility and 
consistency, and, most important of all, enabling the optimization of diagnosis so as to individualize therapy for NHL patients in Mexico.

\section{Acknowledgments}

We thank all the patients for the epidemiological information.

\section{Financial Disclosure}

None to declare.

\section{Conflict of Interest}

The authors have no potential conflict of interest to disclose.

\section{Informed Consent}

Informed consent was obtained.

\section{Author Contributions}

All authors contributed by providing the data of their patients and completing the database. Doctor Eleazar Hernandez Ruiz was the main author since he headed the project; he invited all the colleagues from the country; and together with Doctor Martha Alvarado Ibarra and Doctor Juan Manuel Perez Zuniga carried out the statistical analysis, as well as the final revision and the translation of the text. All authors reviewed and approved the final text.

\section{Data Availability}

The authors declare that data supporting the findings of this study are available within the article.

\section{References}

1. Nogai H, Dorken B, Lenz G. Pathogenesis of non-Hodgkin's lymphoma. J Clin Oncol. 2011;29(14):1803-1811.

2. Vaque JP, Martinez N, Batlle-Lopez A, Perez C, MontesMoreno S, Sanchez-Beato M, Piris MA. B-cell lymphoma mutations: improving diagnostics and enabling targeted therapies. Haematologica. 2014;99(2):222-231.

3. Carrington EM, Tarlinton DM, Gray DH, Huntington ND, Zhan Y, Lew AM. The life and death of immune cell types: the role of BCL-2 anti-apoptotic molecules. Immunol Cell Biol. 2017;95(10):870-877.

4. Sungalee S, Mamessier E, Morgado E, Gregoire E, Brohawn PZ, Morehouse CA, Jouve N, et al. Germinal center reentries of BCL2-overexpressing B cells drive follicular lymphoma progression. J Clin Invest. 2014;124(12):53375351.

5. Scott DW, Gascoyne RD. The tumour microenvironment in B cell lymphomas. Nat Rev Cancer. 2014;14(8):517534.

6. Arber DA. Molecular diagnostic approach to non-Hodgkin's lymphoma. J Mol Diagn. 2000;2(4):178-190.

7. Shankland KR, Armitage JO, Hancock BW. Non-Hodgkin lymphoma. Lancet. 2012;380(9844):848-857.

8. Smith A, Crouch S, Lax S, Li J, Painter D, Howell D, Patmore R, et al. Lymphoma incidence, survival and prevalence 2004-2014: sub-type analyses from the UK's Haematological Malignancy Research Network. Br J Cancer. 2015;112(9):1575-1584.

9. Chao MP. Treatment challenges in the management of relapsed or refractory non-Hodgkin's lymphoma - novel and emerging therapies. Cancer Manag Res. 2013;5:251269.

10. International Non-Hodgkin's Lymphoma Prognostic Factors Project. A predictive model for aggressive nonHodgkin's lymphoma. N Engl J Med. 1993;329(14):987994.

11. Swerdlow SH, Campo E, Pileri SA, Harris NL, Stein H, Siebert R, Advani R, et al. The 2016 revision of the World Health Organization classification of lymphoid neoplasms. Blood. 2016;127(20):2375-2390.

12. WHO. Globocan 2012 - Home. Globocan. 2012.

13. Campo E, Swerdlow SH, Harris NL, Pileri S, Stein H, Jaffe ES. The 2008 WHO classification of lymphoid neoplasms and beyond: evolving concepts and practical applications. Blood. 2011;117(19):5019-5032.

14. Cheson BD, Horning SJ, Coiffier B, Shipp MA, Fisher RI, Connors JM, Lister TA, et al. Report of an international workshop to standardize response criteria for nonHodgkin's lymphomas. NCI Sponsored International Working Group. J Clin Oncol. 1999;17(4):1244.

15. Summary E, List EM, Relevance PH. Diffuse large Bcell lymphoma: 2014 review of cancer medicines on the WHO List of Essential Medicines. 2014:1-8.

16. Perry AM, Diebold J, Nathwani BN, MacLennan KA, Muller-Hermelink HK, Bast M, Boilesen E, et al. Non-Hodgkin lymphoma in the developing world: review of 4539 cases from the International Non-Hodgkin Lymphoma Classification Project. Haematologica. 2016;101(10):1244-1250.

17. Ambinder AJ, Shenoy PJ, Malik N, Maggioncalda A, Nastoupil LJ, Flowers CR. Exploring risk factors for follicular lymphoma. Adv Hematol. 2012;2012:626035.

18. Aozasa K, Zaki MA. Epidemiology and pathogenesis of nasal NK/T-cell lymphoma: a mini-review. ScientificWorldJournal. 2011;11:422-428.

19. Solano M, et al. Diagnostic concordance of pathological methods and reports of hematopathologists compared to local nonspecialized pathologists in the diagnosis of lymphoma in Mexico. Blood. 2018;132(Supplement 1):4727.

20. Kumar A, Sundararajan S, Puvvada S, Persky DO. Limited Stage Aggressive Non-Hodgkin Lymphoma: What Is Optimal Therapy? Curr Treat Options Oncol. 2016;17(9):45.

21. Hu S, Xu-Monette ZY, Tzankov A, Green T, Wu L, Bal- 
asubramanyam A, Liu WM, et al. MYC/BCL2 protein coexpression contributes to the inferior survival of activated B-cell subtype of diffuse large B-cell lymphoma and demonstrates high-risk gene expression signatures: a report from The International DLBCL Rituximab-CHOP Consortium Program. Blood. 2013;121(20):4021-4031; quiz 4250.

22. Schmitz N, Trumper L, Ziepert M, Nickelsen M, Ho AD, Metzner B, Peter N, et al. Treatment and prognosis of mature T-cell and NK-cell lymphoma: an analysis of patients with T-cell lymphoma treated in studies of the German High-Grade Non-Hodgkin Lymphoma Study Group. Blood. 2010;116(18):3418-3425.

23. Jo J, et al. Comparison between CD20-negative and CD20-positive diffuse large B cell lymphoma; characteristics and clinical outcome. Blood. 2010;116:4891 LP-
4891.

24. Zimmermann M, Oehler C, Mey U, Ghadjar P, Zwahlen DR. Radiotherapy for Non-Hodgkin's lymphoma: still standard practice and not an outdated treatment option. Radiat Oncol. 2016;11(1):110.

25. SEER*Explorer: An interactive website for SEER cancer statistics. https://seer.cancer.gov/statfacts/html/nhl.html. Surveillance Research Program, National Cancer Institute. Cited 2020 Dec 22. Available from https://seer.cancer.gov/explorer/.

26. Ji J, Forsti A, Sundquist J, Lenner P, Hemminki K. Survival in non-Hodgkin's lymphoma by histology and family history. J Cancer Res Clin Oncol. 2009;135(12):17111716.

27. Armitage JO. Staging non-Hodgkin lymphoma. CA Cancer J Clin. 2005;55(6):368-376. 